\title{
Guest Editorial: Innovations in Measurement Within the Field of Addiction and Mental Health
}

\author{
Nigel E. Turner
}

Published online: 1 October 2013

(C) Springer Science+Business Media New York 2013

\section{Guest Editorial}

Last summer Masood Zangeneh asked me if I would be interested in acting as a special projects editor with this journal. My first thought was to organize as a topic, the use of computer simulations to study gambling problems, but after some puzzlement over what exactly that meant and what that would entail; I agreed to instead do something on advances in measurement in this field. Consequently the theme for this special issue of the International Journal of Mental Health and Addiction is innovations in measurement within the field of Addiction and Mental Health.

A key part of any scientific research endeavour is to have good tools with which to measure the process under study. As part of a new special issue for the International Journal of Mental Health and Addiction, the current issue highlights recent advances in measurement in the field of addictions and mental health as well as conceptual challenges for these populations. The papers selected for this issue highlight different approaches to measurement in the addictions field. There is a heavy emphasis on gambling related measures because that is my own field of expertise but we have also included papers on substance abuse, ADHD, comorbidity of psychiatric problems and addiction, and exercise dependence.

In social and psychological research measurement has always been difficult because so many of the things we wish to measure cannot be measured directly by physical or biological tests. For example, motivation is understood to be a key component of addiction risk (Stewart et al. 2008), recovery (Marlatt and Gordon 1980; Miller and Rollnick 2002; Miller et al. 1994) and prevention (see Ariyabuddhiphongs 2013) but it is not possible to measure motivation directly. This is also the case for cravings, tolerance, most withdraw symptoms, anxiety, depression, personality, and a large number of other variables that are central to understanding addictions and mental health problems. However, at least physiological

N. E. Turner $(\bowtie)$

Centre for Addiction and Mental Health, 33 Russell Street, Rm. T524, Toronto, ON M5S 2S1, Canada e-mail: nigel_turner@camh.net

N. E. Turner

Dalla Lana School of Public Health, University of Toronto, Toronto, ON, Canada 
measures can be used to detect drug use by using samples of a person's breath, blood, saliva, hair, or urine (Caplan and Goldberger 2001; Couch 2013; Hawks and Chiang 1986; Wish and Gropper 1990). However when it comes to the study of gambling and other "behavioral addictions" the situation is particularly a problem because gambling does not leave a measurable trace with which we can evaluate the person's behavior. In particular, there is no urine screen with which we can objectively measure a person's recent gambling behavior. One of the key issues in establishing problem solving courts for offenders with gambling problems is a lack of a physiological measure to trace compliance to any rule regarding abstinence from gambling (Turner et al. 2013b).

The history of social measurement has been about finding clever means of overcoming the measurement limitation inherent in the field. Although self-report has flaws, as a method, it does provide valuable information about the experience of the respondents. It is important in this field to be aware of the limitations of measurement and to overcome the limitations of such measures by careful construction of the tests. Test construction is a complex business that often takes years and large samples. It can also require the cooperation of clients, counsellors, administrators in hospitals and treatment centres, ethics boards, school boards, and funding agencies in order to facilitate the data collection. In spite of all that hard work, inevitably after the data has been collected, some reviewers will note that the sample size is not large enough for the analysis that is conducted or that measurement was not the gold standard for diagnosis. Also one must live in constant fear that one's measures are just hand waving exercises. This is usually not the case, but it could be.

This process of research however is often not a priority to many people who treat addiction and mental health problems. This is quite understandable as they deal with fractured lives often teetering precariously on the brink of some disaster; the reliability coefficient of a questionnaire on suicide might not be on the top of their mind as they examine the response to individual items on the questionnaire; they see the person, not the measurement issues. The papers in this volume point to a number of different aspects of measurement that are helpful and I do believe push the measurement agenda forward.

Tolchard and Delfabbro (2013) discuss the validity and reliability of a new measure of problem gambling amongst youth the Victorian Gambling Screen-VGS. This population is difficult because previous measures of PG have been criticized for not being appropriate to youth populations and the validity of studies that have found high rates of gambling related problems amongst youth have been criticized. To really understand youth gambling, good measures of this population are needed. In their paper they show that the VGS has sound internal reliability and concurrent validity. According to them, one innovation of this measure is that it focuses on harm, rather than on pathology. However some of the items are perhaps culturally specific to the Australian context (e.g., On a slippery slope). They report that their measure suggests that harm observed in adult populations can also be observed in adolescent problem gamblers. This particular measure looks promising, but thus far it has only been validated on a small number of severe problem gamblers included in the school sample. In addition, the sample did not include any actual treatment cases of problem gambling so the outcome is a bit like the blind (or perhaps semi-sighted) leading the blind. This is a crucial problem in all similar measurement situations because there is no gold standard against which we can validate the disorder. This problem also occurred in a recent study by Tremblay et al. (2010) who have developed a Canadian Adolescent Gambling Inventory. The fact is that very few people seek treatment for problem gambling until they are in their 30s. How can we validate a measure of clinically significant problem gambling for adolescents without a clinical sample of adolescent problem gamblers? The school sample used in this study itself is fairly small $(n=570)$. Given that the identification of 
severe problem gamblers in the youth population is itself problematic, more research is needed to determine if these individuals are in fact problem gamblers. However, these authors do offer a very promising measure that may advance the study of youth gambling considerably.

My own contribution to this issue (Turner et al. 2013a) is a publication of a measure of situational risk for problem gambling: the Centre for Addiction and Mental Heath-Inventory of Gambling Situations (CAMH-IGS). This long awaited paper reports on a confirmatory factor analysis of the CAMH-IGS. The analysis confirmed the basic factor structure and found only a small number of parameters that should be changed. The CAMH-IGS is based on a cognitive-behavioural approach to addiction that sees excessive gambling as a pattern of behaviour which is learned, and which can be changed. The CAMH-IGS is designed to determine the patterns of behaviour, thoughts or feelings, which may trigger problematic gambling, with the goal of developing tailored treatment and relapse-prevention approaches for clients. This information can be used by a therapist to develop an individualized treatment plan for those affected by problem gambling. Six of these subscales are derived directly from work we have previous published on substance abuse (e.g., negative emotions, conflict with others, testing personal control, pleasant emotions, social pressure, and urges and temptations; Pashaei, et al. 2013; Sklar et al. 1997, 1998; Sklar and Turner 1999; Turner et al. 1997). In recognition of the unique characteristics of gambling the CAMH-IGS includes four gambling specific subscales: need for excitement (NEX), confidence in skill $(C S)$, winning and chasing (WC), and worried about debts (WD). These scales attempt to capture the idea of being caught in the gambling cycle by following the gambler from initial motivations (e.g., NEX, CS), through increasing levels of cognitive entrapment (e.g., WC), to gambling in the hope of paying debts (e.g., WD). We are currently collecting additional data on the CAMH-IGS through an on-line application and will be examining the measure to further cross validate it. The CAMH-IGS is available on the Internet free of charge: www.problemgambling.ca/EN/ResourcesForProfessionals/Pages/IGS.aspx.

The paper by DeMarce et al. (2013) examines the validity of the Structured Clinical Interview for DSM-IV (SCID) among veterans seeking treatment for Substance Use Disorders (SUD). Given that the DSM criterion are considered to be the gold standard for diagnosis, it is important to push for more thorough validation of psychiatric measures such as the SCID. In this paper, the authors tested the concurrent, discriminant, and predictive validity of the SCID for SUDs and antisocial personality disorder (APD). The results supported the concurrent, discriminant, and predictive validity of the SCID I diagnoses of alcohol use disorders, and offers strong support for the concurrent and discriminant validity of drug use disorders (DUD). They report mixed support for the concurrent validity of APD and no support for the predictive validity for DUDs or APD. Thus the results offer a mix view of the diagnostic gold standard. Although the SCID was shown to have some validity, it is not without its weaknesses.

In a similar vein Matthys et al. (2013) report on the development of an evidence based guideline for the Dual Diagnosis of attention deficit hyperactivity disorder (ADHD) and substance use disorder (SUD) based on data from focus group interviews. Oftentimes researchers rush toward quantitative measures of disorders without first learning as much about the disorder from clients as they can. In this paper, they obtained information about the expectations and experiences of patients with ADHD and SUD. They report that ADHD is often under diagnosed in addicted patients. They also report that the analysis revealed a great difference between addicted inpatients and outpatients as to the possibilities of diagnosing and treating ADHD. Furthermore, they suggest that it is difficult to make a proper diagnosis in patients who are not fully abstinent, as there are no validated diagnostic instruments for 
this target group, and that research is needed to develop diagnostic tools for this population. This is a crucial problem for SUD. Although ADHD is known to be associated with SUD, diagnosis is obscured by the substance abuse. Knowing if the client has ADHD however might help the clinician in treatment planning. They report that the positive experiences in the residential addiction services with non-pharmacological methods of treatment for addiction offer a perspective to develop specific methodologies that can be adapted to patients with comorbid ADHD. This paper is important because it focuses on the use of qualitative methods to examine basic problems in utilizing diagnostic measures and possible solutions.

The paper by Ariyabuddhiphongs (2013) is quite different from the rest, but was included because it highlights another important aspect of good measurement: the need for more longitudinal work. The paper is a literature review of problem gambling prevention methods. The paper breaks them into programs that focus on prevention (1) before gambling has become a problem (primary prevention) that deal with misconceptions and attitudes, (2) during gambling that focus on structural changes to gambling machines and warning messages, and (3) after gambling that involve relapse prevention and self-exclusion. Ariyabuddhiphongs (2013) reports that the effectiveness of each type of gambling problem prevention method has limited evidence of success. For example, he points out that school based primary prevention problems have been successful at teaching some basic skills, but have not produced any evidence of a long term change in gambling behaviour. The absence of evidence however should not be taken as the absence of an effect. A difficulty with research in this area is the lack of longitudinal research. Due to the low rates of problem gamblers to properly measure prevention of problems amongst teens would require following an enormous controlled sample for as much as 20 years or more. Very few studies have used longitudinal methods and none have even approached the sample size needed to detect a long term differences in the prevalence of pathological gambling. ${ }^{1}$ Ariyabuddhiphongs (2013) suggests that future research should focus on theory, longitudinal studies, internet gambling, and cross-national research. His review is important because it highlight a fundamental gap in knowledge of prevention methods and outcome data. He goes on to state that no prevention measure seemed to be more effective than the gamblers' motivation to control their own gambling behaviors. This paper helps focus attention on the various types of prevention strategies and areas where the research can be improved.

Oftentimes improving a therapeutic outcome involves training staff. Evaluating the effectiveness of staff training is therefore crucial to solving mental health and addiction problems. Heslop et al. (2013) discuss the evaluation of an education intervention with nurses to improve the assessment and treatment of psychiatric patients with co-morbid substance abuse problems. According to the authors up to $60 \%$ of people admitted to acute mental health services in Australia present with a clinically significant co-occurring drug and/or alcohol problem, and these individuals experience poorer health outcomes compared to patients with a mental illness that do not have co-morbid alcohol and drug problems. Staff at many mental health institutions are often too busy to spontaneously spot comorbid problems. In addition nurses working in the area do not have the knowledge and skills and confidence to work effectively with this patient population. The paper evaluates an invivo education program at an acute mental health inpatient unit in Western Australia to educate nurse in assessing problems and implementing a brief intervention. The study reports a significant improvement in nurses' knowledge along with increased clinical confidence and skills to identify, assess, and manage this group of patients and to provide

\footnotetext{
${ }^{1}$ For example, I estimate that it would take at least 45,000 students followed for 20 years to detect a difference of say $0.25 \%$ in the prevalence of disordered gambling between an intervention group and a control group.
} 
them with information and referral to appropriate agencies in the community. The study provides a great deal of detail about the type of change that was achieved.

A very different paper is offered by Thompson and Corr (2013). They used experimental methods to examine the effect of a feedback-response pause that normalises response perseveration deficits in pathological gamblers. They note that failure to inhibit punished responses is central to problematic gambling. That is PGS (and addicts in general) do not seem to learn from punishment. They used a computerised card playing game to determine if this failure to learn from punishment can be reduced by imposing a delay between feedback from the previous trial and the opportunity to play the next card. They found that compared to the Control group, problematic gamblers perseverated longer and lost more money on the Standard task, but this deficit was abolished by the imposition of a $5 \mathrm{~s}$ pause. They argue that the $5 \mathrm{~s}$ delay strengthened inhibitory control. Their finding has major implication for the speed of play on gambling machines. In recent years the speed of play has increased from 1 spin per $6 \mathrm{~s}$ to as fast as 1 spin per $3 \mathrm{~s}$. However, it is unknown if the results of a laboratory study would translate to an actual casino venue. Speed of play alone however cannot explain all problems. Table games are typically run at a much more leisurely pace that creates a delay between bets. The revenue figures from casinos in Macau where table game produce most of the revenue (O'keffe 2013 June; Wong 2013 May) would suggest that these relatively slow games can also be highly addictive. Nonetheless, this examination of how a structured delay between games augments learning from losses may lead to the development of safer gambling machines.

Nuzzo et al. (2013) examined the rate of exercise dependence symptoms in a sample of exercise science students in the United States. The study reports that exercise science students are more likely to show symptoms on exercise dependence. In an age where there is a great focus on obesity, it is interesting to see the opposite end of the spectrum also pathologized. They report that exercise science students scored significantly higher on the scale than non-exercise students. In addition, they scored higher on all of the items. The issue of another excessive behaviour that can become problematic is interesting. Like all areas of behavioural addiction (or process disorders), the definition of exercise dependence is problematic. In particular in other behavioral addictions such as video gaming there is no gold standard to define exactly when the behavior is out of control (see Turner, et al. 2012). In addition exercise may offer some unique challenges. For example, how does one tell the difference between tolerance and goal oriented training (e.g., body building) because both involve increasing exercise to achieve the desired goal. Another unique feature of exercise addictions is that one of the potential problems from excessive exercise is physical injury such as repetitive strain injuries. These injuries might make an exercise addiction selflimiting, that is a person might reach a point where the pain from exercise forces the person to stop exercising. This "bottom" might occur at a relatively earlier stage compared to a drug addiction. Another big question for exercise addiction is do we need counselling programs for people with exercise dependency? I look forward to seeing further developments in this area as we come to more fully appreciate the various types of behavior that may be potentially addictive.

In summary, this volume highlights a variety of studies that address measurement issues in the field of mental health and addictions. Each paper is unique and adds substantively to the dialogue in this field. It is my hope that by highlighting the measurement issues addressed by each of these papers, I can encourage more people in this field to care about these measurement issues. This is not to say measurement should ever take priority over clinical issues - definitely it should not. But a better appreciation of the importance of measurement issues would facilitate an improvement in diagnosis, client care, prevention, and staff training. 
Conflict of Interest Declaration None.

\section{References}

Ariyabuddhiphongs, V. (2013). Problem gambling prevention: before, during, and after measures. International Journal of Mental Health and Addiction, 1-15.

Caplan, Y. H., \& Goldberger, B. A. (2001). Alternative specimens for workplace drug testing. Journal of Analytical Toxicology, 25(5), 396-399.

Couch, D. (2013). Oral fluid collections and considerations. DATIA Focus, Spring 2013, 9-14. http:// www.datia.org/view-the-latest-electronic-version-of-datia-focus.html.

DeMarce, J.M., Lash, S.J., Parker, J.D., Burke, R.S., Grambow, S.C. (2013). Validity of the structured clinical interview for DSM-IV among veterans seeking treatment for substance use disorders. International Journal of Mental Health and Addiction.

Hawks, R. L., \& Chiang, C. N. (1986). Urine testing for drugs of abuse. Rockville, MD: National Institute on Drug Abuse.

Heslop, K., Ross, C., Osmond, B., \& Wynaden, D. (2013). The Alcohol Smoking and Substance Involvement Screening Test (ASSIST) in an acute mental health setting. International Journal of Mental Health and Addiction, 1-18.

Marlatt, G. A., \& Gordon, J. R. (1980). Determinants of relapse: Implications for the maintenance of behaviour change. In P. O. Davidson \& S. M. Davidson (Eds.), Behavioral medicine: Changing health lifestyles (pp. 410-452). New York: Brunner-Mazel.

Matthys, F., Joostens, P., Stes, S. Tremmery, S., Sabbe, B. (2013). The construction of the first validated (evidence based) guideline for dual diagnosis of ADHD and SUD. Data from Focus Groups International Journal of Mental Health and Addiction.

Miller, W. R., \& Rollnick, S. (2002). Motivational Interviewing: Preparing people to change. New York: Guilford press.

Miller, W. R., Zweben, A., DiClemente, C. C., \& Rychtarik, R. G. (1994). Motivational enhancement therapy manual. Washington, DC: National Institute on Alcohol Abuse and Alcoholism.

Nuzzo, J.L., Schindler, C.L., Ryan, W.J. (2013). Exercise dependence symptoms in a sample of exercise science students in the United States International. Journal of Mental Health and Addiction.

O'keffe, K. (2013). Macau gambling revenue up 14\% on year in May at MOP29.59 Bln. The Wall Street Journal, Monday, June 3, 2013. http://online.wsj.com/article/BT-CO-20130603-700228.html.

Pashaei, T., Razaghi, O., Rahimi, A., Tabatabaei, G. M., Moeeni, M., Turner, N., Sharifi, V., \& Shojaei, D. (2013). Assessing of the validity and reliability of the farsi version of inventory drug-taking situations (IDTS). Iranian Journal of Psychiatry, 8(2), 80-85.

Sklar, S. M., \& Turner, N. E. (1999). A brief measure for the assessment of coping self-efficacy among alcohol and other drug users. Addiction, 94, 723-729.

Sklar, S. M., Annis, H. M., \& Turner, N. E. (1997). Development of the drug-taking confidence questionnaire: a measure of coping self-efficacy. Addictive Behaviors, 22, 655-670.

Sklar, S. M., Annis, H. M., \& Turner, N. E. (1998). Group comparisons of coping self-efficacy between alcohol and cocaine abusers seeking treatment. Psychology of Addictive Behaviors, 13(2), 123-133.

Stewart, S. H., Zack, M., Collins, P., Klein, R. M., \& Fragopoulos, F. (2008). Sub-typing pathological gamblers on the basis of affective motivations for gambling: Relations to gambling problems, drinking problems, and affective motivations for drinking. Psychology of Addictive Behaviors, 22, 257-268.

Thompson, S.J., \& Corr, P.J. (2013). A feedback-response pause normalises response perseveration deficits in pathological gamblers. International Journal of Mental Health and Addiction.

Tolchard, B., \& Delfabbro, P. (2013). The Victorian gambling screen: validity and reliability in an adolescent population. International Journal of Mental Health and Addiction.

Tremblay, J., Wiebe, J., Stinchfield, R., \& Wynne, H. (2010). The Canadian adolescent gambling inventory: Phase III final report. Toronto: Canadian Centre on Substance Abuse and the Interprovincial Consortium on Gambling Research.

Turner, N. E., Annis, H. M., \& Sklar, S. M. (1997). Measurement of antecedents of drug use and drinking: Psychometric Properties of the Inventory of Drug Taking Situations (IDTS). Behavior Research and Therapy, 35, 465-483.

Turner, N. E., Paglia-Boak, A., Ballon, B., Cheung, J. T. W., Adlaf, E. M., Henderson, J., Chan, V., Rehm, J., Hamilton, H., \& Mann, R. E. (2012). Prevalence of problematic video gaming among Ontario adolescents. International Journal of Mental Health and Addiction, 10(6), 877-889. doi:10.1007/ s11469-012-9382-5. 
Turner, N.E., Littman-sharp, N., Toneatto, T., Liu, E., Ferentzy, P. (2013a). Centre for addiction and mental health inventory of gambling situations: evaluation of the factor structure, reliability, and external correlations. International Journal of Mental Health and Addiction.

Turner, N.E., Matheson, F.I., Ferentzy, P., McAvoy, S., Myers, C., Littman-Sharp, N., Malat, J. (2013b). A qualitative study of programs for problem gambling in the correctional population using interviews with experts in the field. Reported submitted to the Ontario Problem Gambling Research Centre www.gamblingresearch.org.

Wish, E. D., \& Gropper, B. A. (1990). Drug testing by the criminal justice system: methods, research, and applications. Crime \& Just, 13, 321.

Wong, SW. (2013). Slots are to Las Vegas as baccarat is to Macau: A game analysis. Paper presented at the International Conference of Gambling and Risk Taking, Las Vegas Nevada, May 2013. 